\title{
Experimental and theoretical study of adsorption of L-cysteine on the passivation and corrosion inhibition of aluminum alloy in alkaline environment
}

\author{
Said Kharacha 1,*, M'hamed Belkhaouda ${ }^{1}$, Lahcen Bammou ${ }^{2}$, Ahmed Batah ${ }^{2}$, Ilyasse Bazzi ${ }^{2}$, Rachid \\ Salghi $^{2}$, Souad El Issami ${ }^{1}$ and Mustapha Hilali ${ }^{1}$ \\ ${ }^{1}$ Laboratory of Materials \& Environmental, Faculty of Science, Ibn Zohr University, Agadir, Morocco \\ ${ }^{2}$ Laboratory of Environmental Engineering and Biotechnology, ENSA, University Ibn Zohr, PO Box 1136, \\ 80000 Agadir, Morocco
}

\begin{abstract}
L-Cysteine (L-Cyst) was tested as a corrosion inhibitor of 3003 aluminum alloy (AA3003) in $\mathrm{Na}_{2} \mathrm{CO}_{3}$ $0.1 \mathrm{M}+\mathrm{NaCl} 1 \mathrm{M}$ solution. The inhibition action of this inhibitor was studied by using electrochemical impedance spectroscopy (EIS), potentiodynamic polarization (PDP), and cyclic voltammetry (CV) techniques. The temperature effect on the inhibition efficiency was studied in the range from 298 to $328 \mathrm{~K}$, and the values of activation thermodynamic parameters were calculated and explained. Experiment results show that inhibition efficiency increases with the increase of L-Cysteine concentration, and its inhibition efficiency reaches $92 \%$ at $10^{-3} \mathrm{M}$. The inhibition efficiency decreases slightly with the elevation of a corrosive medium temperature. Analysis of the polarization curves revealed that L-Cyst is considered a mixed inhibitor. The results from electrochemical measurements and theoretical calculations are in good agreement. The morphological changes of the surface during corrosion, in the presence and absence of the inhibitor, were studied by scanning electron microscopy (SEM).
\end{abstract}

Keywords: Aluminum Alloy; Corrosion inhibition; PDP; CV; EIS; DFT; L-Cysteine.

\section{Introduction}

Aluminum is used as packaging in the food industry; in addition, it is oxidizable in a chlorinated alkaline medium; indeed, the choice is justified by this last property.

Corrosion of Aluminum and its alloys has attracted much attention from many researchers due to their high mechanical intensity, low cost, low density, and good machinability. They have been widely used in industrial applications, especially in constructions, electronics, packing, storage, transportation equipment, and machinery ${ }^{1-6}$. Efforts have been made to protect the aluminum surface's integrity in an aggressive alkaline medium or another corrosive environment. In recent decades, the addition of inhibitors has been considered the most common approach to hinder Aluminum's corrosion ${ }^{7-10}$. The inhibition of corrosion materials by non-toxic organic inhibitors is an encouraging solution that can effectively replace the usual toxic chemical inhibitors such as azole and thiol compounds ${ }^{11-13}$. Organic inhibitors' mechanism action is explained by physical and/or chemical adsorption on the metal

*Corresponding author: Said Kharacha

Email address: said.kharacha@edu.uiz.ac.ma

DOI: http://dx.doi.org/10.13171/mjc02103041563sk surface ${ }^{12,14-16}$. This inhibitive action depends on the physicochemical properties of the inhibitor atoms, such as the functional group and the aromaticity and the presence of the heteroatoms ${ }^{17-19}$, without forgetting the nature of the surface, the temperature, and the pressure of the reaction ${ }^{20}$.

Azzouyahar and co-workers investigated the corrosion inhibition of AA3003 in $\mathrm{Na}_{2} \mathrm{CO}_{3}$ by Nigella Sativa Oil ${ }^{21}$. The results of this study revealed that Nigella Sativa oil acts as a suitable inhibitor of aluminum corrosion in a solution of $0.1 \mathrm{M} \mathrm{Na}_{2} \mathrm{CO}_{3}$; the Inhibition efficiency reaches $91 \%$ for $4 \mathrm{~g}$. $\mathrm{L}^{-1}$ at $298 \mathrm{~K}$

Barouni et al. tested some amino acid compounds such as Arginine (Arg), Cysteine (Cys), Glycine (Gly), Lysine (Lys), and Valine (Val) on the behavior of copper corrosion in $1 \mathrm{M} \mathrm{HNO}_{3}{ }^{22}$. This study shows that Cys is the best inhibitor of copper corrosion in $1 \mathrm{M} \mathrm{HNO}_{3}$; the inhibition efficiency attains $61 \%$ at $10^{-3} \mathrm{M}$.

Chadili et al worked on the inhibition of the corrosion inhibition of Aluminum alloy 3003 in a hydrochloric

acid medium using oil mill liquid by-product (OMW)

Received December 12, 2021

Accepted January 5, 2021

Published March 4, 2021 
as an inhibitor. The experimental results reveal that OMW has a good inhibiting effect on the corrosion of AA3003 alloy in the tested solution and acts as a cathodic inhibitor ${ }^{23}$.

The purpose of the present work is to investigate the corrosion inhibition action of L-cysteine named 2-amino-3-mercapto propanoic acid shown in Figure 1 on aluminum alloy's corrosion $\mathrm{Na}_{2} \mathrm{CO}_{3}$ $0.1 \mathrm{M}+\mathrm{NaCl} 1 \mathrm{M}$ solution. The techniques solicited were: Potentiodynamic polarization curves, cyclic voltammetry (CV), and electrochemical impedance spectroscopy (EIS). Effect of inhibitor concentration, the temperature on the corrosion, inhibition, and passivation behavior were thoroughly investigated and discussed. The thermodynamic feasibility of adsorption of the L-Cyst inhibitor molecule on the aluminum surface was also studied. Scanning electron microscopy is used to look at surface morphological changes during polarization studies, with and without inhibitor.<smiles>NC(CS)C(=O)O</smiles>

Figure 1. Chemical structure of L-cysteine

\section{Experimental}

\subsection{Working electrode}

The sample used in this study is 3003 aluminum alloy with a chemical composition (wt.\%): $\mathrm{Si}, 0.12, \mathrm{Fe}$, $0.31, \mathrm{Cu}, 0.008, \mathrm{Mn}, 1.27, \mathrm{Mg}, 0.95$, and remainder $\mathrm{Al}^{24}$.

The working specimen was cut from the plate, leaving only $0.16 \mathrm{~cm}^{2}$ of the surface area exposed to the electrolyte. Before each experiment, the working electrode was mechanically polished with fine grades of emery papers (400 - 1200 grade). Then it was degreased with acetone, washed with double distilled water, and dried before immersing in the corrosion medium. All experiments were performed at different temperatures under the same experimental conditions.

\subsection{Corrosive solution}

The corrosive medium was $\mathrm{Na}_{2} \mathrm{CO}_{3} 0.1 \mathrm{M}+\mathrm{NaCl} 1 \mathrm{M}$ solution prepared by dissolving $10.6 \mathrm{~g}$ of sodium carbonate and $58.44 \mathrm{~g}$ of sodium chloride in $1000 \mathrm{~mL}$ of double-distilled water. The solution tests are freshly prepared before each experiment. The inhibitor's concentration range was $10^{-3}$ to $10^{-6} \mathrm{M}$. All electrochemical tests have been performed in aerated solution at $\mathrm{pH}=11$.

\subsection{Electrochemical techniques}

Electrochemical measurements were carried out by using an electrochemical workstation, versa STAT 3 potentiostat piloted by versa studio software. The arrangement used was a conventional three-electrode compartment glass cell with a platinum counter electrode and a saturated calomel electrode (SCE) as reference. The working electrode was made of aluminum alloy (AA3003). All the values of potential are referred to the SCE. The polarization studies were carried out immediately after the EIS studies on the same electrode without further surface treatment.

\subsubsection{Potentiodynamic polarization studies}

Finely polished aluminum alloy specimen was exposed to the corrosion medium of $\mathrm{Na}_{2} \mathrm{CO}_{3}$ $0.1 \mathrm{M}+\mathrm{NaCl} 1 \mathrm{M}$ solution in the presence and absence of the inhibitor at different temperatures $(298-328 \mathrm{~K})$ and allowed to establish a steady-state open circuit potential (OCP).

The potentiodynamic current- potential curves were recorded by polarizing the specimen from $-1800 \mathrm{mV}$ to $0 \mathrm{mV}$ at a scan rate of $1 \mathrm{mV} \cdot \mathrm{s}^{-1}$.

\subsubsection{Electrochemical impedance spectroscopy studies (EIS)}

The impedance measurements were carried out in the frequency range of $10 \mathrm{kHz}$ to $0.1 \mathrm{~Hz}$, at the $\mathrm{OCP}$, by applying $10 \mathrm{mV}$ wave $\mathrm{AC}$ voltage. The double-layer capacitance $\left(\mathrm{C}_{\mathrm{dl}}\right)$ and the charge transfer resistance $\left(\mathrm{R}_{\mathrm{ct}}\right)$ were calculated from the Nyquist or Bode plots.

At least three similar results were considered in all the above measurements, and their average values are reported.

\subsection{Scanning Electron Microscope (SEM)}

The aluminum alloy's surface morphologies immersed in $\mathrm{Na}_{2} \mathrm{CO}_{3} 0.1 \mathrm{M}+\mathrm{NaCl} 1 \mathrm{M}$ solution for 20days with and without the inhibitor L-Cyst were observed via SEM (TESCAN VEGA 3) at an accelerating voltage of $20 \mathrm{kV}$.

\subsection{Quantum Chemical Calculation}

The quantum theoretical calculations were carried out with the Gaussian 03 program package ${ }^{25}$. The complete geometry optimization of the undertaken MTP as corrosion inhibitor was carried out at DFT (Density Functional Theory) using the hybrid functional B3LYP level taking into account the exchange and the correlation with Beck's three parameters exchange functional along with Lee and al. non-local correlation functional 26,27. All Calculations of DFT/B3LYP theory were done using $6-31 G(d, p)$ basis set. This approach is widely utilized in the analysis of the characteristics of the corrosion process. The following quantum chemical parameters were evaluated from the optimized molecular structure: the dipole moment $(\mu)$, the energy of the highest occupied molecular orbital $\left(\mathrm{E}_{\mathrm{HOMO}}\right)$, the energy of the lowest unoccupied molecular orbital $\left(\mathrm{E}_{\mathrm{LUMO}}\right)$, the energy band gap $\left(\Delta \mathrm{E}_{\mathrm{gap}}=\mathrm{E}_{\mathrm{HOMO}}-\mathrm{E}_{\mathrm{LUMO}}\right)$, the electron affinity (A) (the ionization potential (I) and the number of transferred electrons $(\Delta N)$.

\section{Results and Discussion}

\subsection{OCP measurement}


OCP measurement is a simple additional tool that provides complementary information to EIS results regarding the corrosion undergone by the AA3003 after exposure to aggressive solutions ${ }^{28}$. Before each polarization manipulation or EIS, the working electrodes were immersed in $\mathrm{Na}_{2} \mathrm{CO}_{3} 0.1 \mathrm{M}+\mathrm{NaCl} 1 \mathrm{M}$ solution for $30 \mathrm{~min}$ to access the free corrosion potential or the quasi-stationary $\mathrm{E}_{\text {ocp }}$ value. The plots of $E_{\text {ocp }}$ vs time of AA3003 in the absence and presence of inhibitor are given in Figure 2.

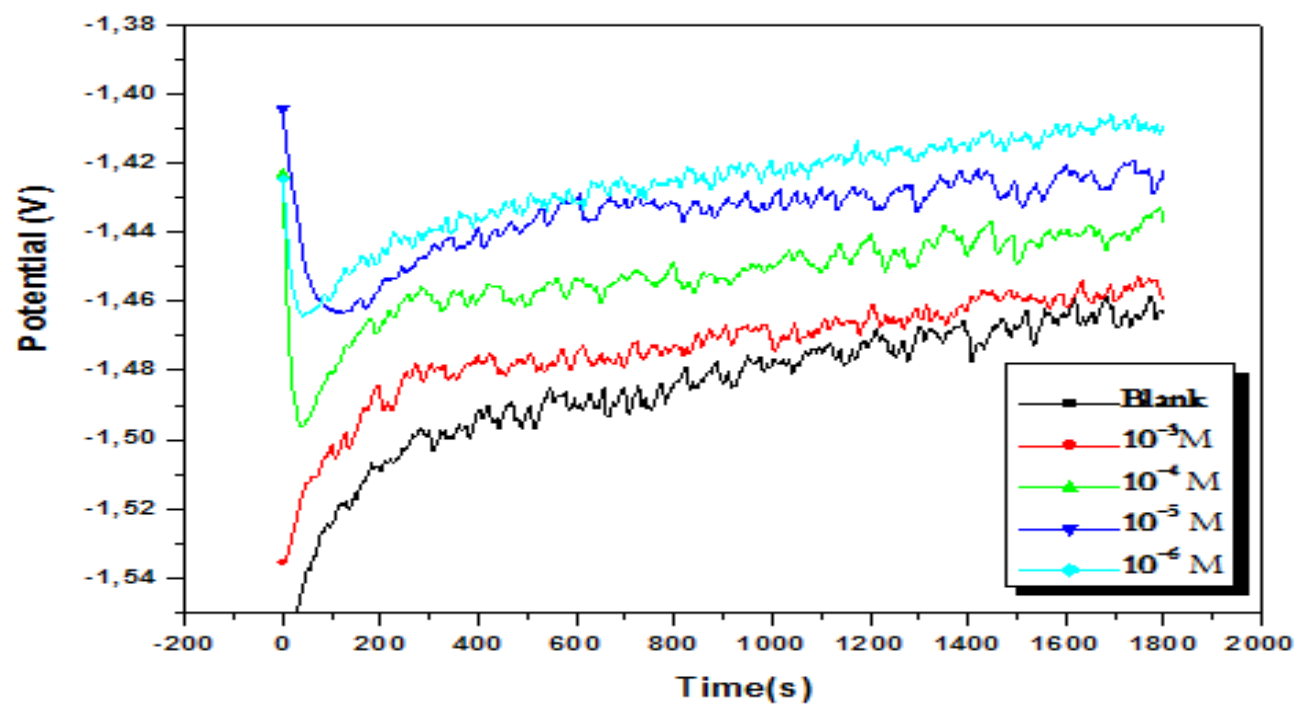

Figure 2. OCP plots for $\mathrm{AA} 3003$ in $\mathrm{Na}_{2} \mathrm{CO}_{3} 0.1 \mathrm{M}+\mathrm{NaCl} 1 \mathrm{M}$ containing $\mathrm{L}-\mathrm{Cyst}$ at different concentrations

The OCP is the potential of the working electrode concerning reference electrode without applied any potential or current. It is required to maintain the stability of OCP before running the polarization and EIS experiments. Figure 2 shows the variation of OCP of working electrode with time in uninhibited and inhibited system at $298 \mathrm{~K}$.

In the presence of L-Cyst, the potential has been evaluated towards higher values. The potential stabilizes towards the value $-1440 \mathrm{mV} / \mathrm{ECS}$, after which the potential begins to decrease with the increase of the immersion time. Translates the system's instability, whereas for aluminum one observes a rather regular decay that would indicate weak protection of the natural film of alumina.

\subsection{Behavior of $\mathbf{A A 3 0 0 3}$ in alkaline medium}

Figure 3 shows the potentiodynamic polarization curve of AA3003 in an alkaline solution. In the cathodic domain, Tafel behavior characterized by linear regions in the proximity of the potential of corrosion indicates that the process of reduction of the water is an activation control ${ }^{29-31}$ :

$$
2 \mathrm{H}_{2} \mathrm{O}+2 \mathrm{e}^{-} \longrightarrow 2 \mathrm{OH}^{-}+\mathrm{H}_{2}
$$

Examination of the anode curve shows that AA3003 exhibits a passivation phenomenon with rupture of passivity. Indeed, starting from OCP, the anodic current density increases with the electrode potential to reach the passivation stage. In this stage, the anodic current density is almost constant, and nomad passivation current density $\mathrm{I}_{\text {pass. }}$ This phenomenon is probably attributed to the formation of a passive film on the AA3003 surface. When the anodic current density increases abruptly, the pitting potential $\mathrm{E}_{\text {pit }}$ is reached.

The following reaction mechanism can represent the dissolution of the metal:

$$
\begin{aligned}
& \mathrm{Al}^{3+}+3 \mathrm{OH}^{-} \longrightarrow \mathrm{Al}(\mathrm{OH})_{3}+3 \mathrm{e}^{-} \\
& \mathrm{Al}(\mathrm{OH})_{3}+\mathrm{OH}^{-} \longrightarrow \mathrm{Al}(\mathrm{OH})_{4}^{-}
\end{aligned}
$$

At alkaline $\mathrm{pH}$ the aluminum hydroxide dissolves to give the ion $\mathrm{AlO}_{2}^{-}$very soluble according to the reaction balance ${ }^{32}$ :

$$
\mathrm{Al}(\mathrm{OH})_{4}^{-} \longrightarrow \mathrm{AlO}_{2}^{-}+2 \mathrm{H}_{2} \mathrm{O}
$$

The Nyquist diagram is presented in Figure 4. calculated from the difference between the reel impedance value at high frequency and their value at a low frequency of loop (loop diameter). The semicircle loop indicates that a charge transfer process mainly controls the corrosion of aluminum alloy.

\subsection{Effect of L-Cyst concentration}

\subsubsection{Potentiodynamic Polarization Curves}

The effect of L-Cyst was studied using potentiodynamic polarization curves. Figure 3 shows the obtained results of AA3003 in $\mathrm{Na}_{2} \mathrm{CO}_{3}$ $0.1 \mathrm{M}+\mathrm{NaCl} 1 \mathrm{M}$ solution in the absence and presence of a tested compound at different concentrations. 


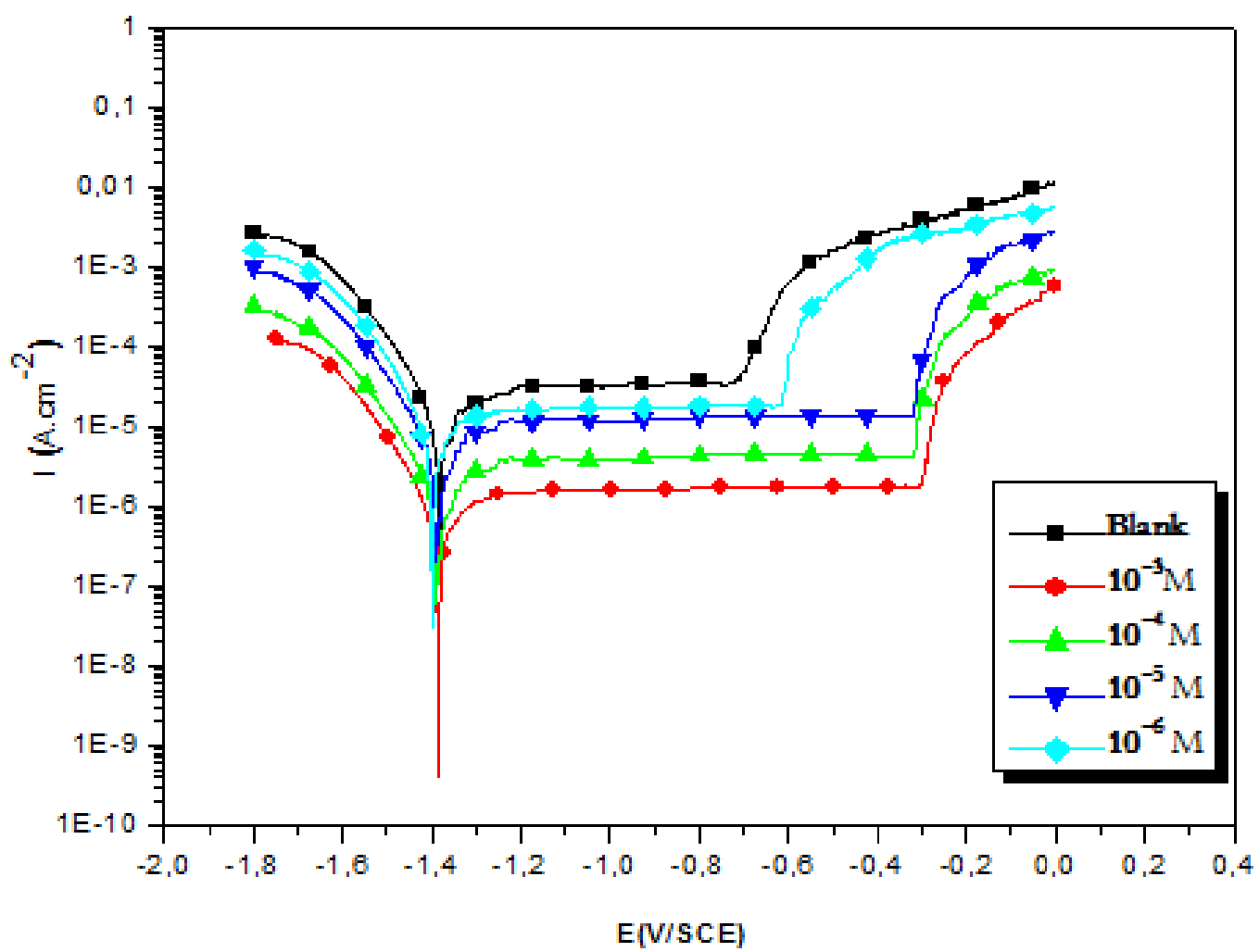

Figure 3. Polarization curves for $\mathrm{AA} 3003$ in $\mathrm{Na}_{2} \mathrm{CO}_{3} 0.1 \mathrm{M}+\mathrm{NaCl} 1 \mathrm{M}$ solution with and without L-Cyst at different concentrations $(\mathrm{T}=298 \mathrm{~K})$

The polarization curves show the reactions of the anodic and current density was slowed with the addition of tested compound for all envisaged concentrations. Generally, the organic inhibitors acted by physical or chemical adsorption or both on the metal's surface. The slowdown of reactions, anodic and cathodic, is marked by the rise of concentration inhibitors. The corrosion parameters, including corrosion potential $\left(\mathrm{E}_{\text {corr }}\right)$, current density $\left(\mathrm{I}_{\mathrm{corr}}\right)$, cathodic Tafel slope $\left(\beta_{\mathrm{c}}\right)$, passivation current density $\left(\mathrm{I}_{\text {pass }}\right)$, pitting potential $\left(\mathrm{E}_{\mathrm{pit}}\right)$ and inhibition efficiency $\left(\mathrm{E}_{\mathrm{I}} \%\right)$ are listed in Table 1.

The shape of the cathodic and anodic curves is not changed. It is found that $\mathrm{I}_{\text {pass }}$ decreases with the increase of the inhibitory concentration to reach a value of $3 \mu \mathrm{A} / \mathrm{cm}^{2}$ for a concentration of $10^{-3} \mathrm{M}$.

$\Delta \mathrm{E}$ being the difference between $\mathrm{E}_{\mathrm{pit}}$ and $\mathrm{E}_{\text {corr }}$ $\left(\Delta E=E_{p i t}-E_{c o r r}\right)$, from the results obtained, we find that $\Delta \mathrm{E}$ increases with the concentration of the inhibitor. However, $\mathrm{E}_{\mathrm{pit}}$ moves towards positive values. We can say that this type of inhibitor is effective for passive materials.

No effective change was observed in the corrosion potential $\left(\mathrm{E}_{\text {corr }}\right)$ value concerning the blank. Both anodic and cathodic polarization is influenced simultaneously, almost to the same extent, which indicates L-Cyst's influence on both the anodic and the cathodic reactions, water reduction, and metal dissolution. If the corrosion potential displacement is more than $85 \mathrm{mV}$ for the blank's corrosion potential, the inhibitor can be seen as a cathodic or anodic type ${ }^{33}$. However, in the present case, the maximum displacement in $\mathrm{E}_{\text {corr }}$ is $24 \mathrm{mV}$ which is much less than $85 \mathrm{mV}$, suggesting a mixed inhibitor mode.

The inhibition efficiency is calculated following the relationship:

$\mathbf{E}_{\mathbf{I}} \%=\frac{\mathbf{I}_{\text {corr }}-\mathrm{I}_{\text {corr }}^{\prime}}{\mathrm{I}_{\text {corr }}} \times 100$

Where, $\mathrm{I}_{\text {corr }}$ and $\mathrm{I}_{\text {corr }}$ are the corrosion current density values without and with the inhibitor, respectively. We noted that $I_{\text {corr }}$ and $I_{\text {corr }}$ were determined by extrapolation of cathodic Tafel lines to the corrosion potential.

Table 1 shows that when more inhibitors were added into the corrosive solution, the corrosion current density decreased, and the inhibition efficiency increased.

The results show that in the inhibitor's presence, the corrosion rate is considerably decreased, justifying by the decrease the intensity of corrosion current. For instance, for the curve before adding L-Cyst to the corrosive medium $\left(\mathrm{Na}_{2} \mathrm{CO}_{3} 0.1 \mathrm{M}+\mathrm{NaCl} 1 \mathrm{M}\right)$, the corrosion current density was $142 \mu \mathrm{A} / \mathrm{cm}^{2}$, and it was considerably reduced to $13 \mu \mathrm{A} / \mathrm{cm}^{2}$ for L-Cyst at $10^{-3} \mathrm{M}$. and the other hand, observing that the current density is decreased in both cathodic and anodic branches (Figure 3). 
Table 1. Polarization parameters of $\mathrm{AA} 3003$ in $\mathrm{Na}_{2} \mathrm{CO}_{3} 0.1 \mathrm{M}+\mathrm{NaCl} 1 \mathrm{M}$ at $298 \mathrm{~K}$ in the absence and presence of L-Cyst.

\begin{tabular}{|c|c|c|c|c|c|c|c|c|}
\hline Inhibitor & $\begin{array}{c}\text { Conc } \\
(\mathrm{M})\end{array}$ & $\begin{array}{c}-\mathrm{E}_{\text {corr }} \\
(\mathrm{mV} / \mathrm{SCE})\end{array}$ & $\begin{array}{c}\mathrm{I}_{\text {pass }} \\
\left(\mu \mathrm{A} \mathrm{cm} \mathrm{cm}^{-2}\right)\end{array}$ & $\begin{array}{c}\mathrm{E}_{\text {pit }} \\
(\mathrm{mV} / \mathrm{SCE})\end{array}$ & $\begin{array}{c}\Delta \mathrm{E}=\mathrm{E}_{\mathrm{pit}} \\
\mathrm{E}_{\mathrm{corr}} \\
(\mathrm{mV} / \mathrm{SCE})\end{array}$ & $\begin{array}{c}-\beta_{\mathrm{c}} \\
\left(\mathrm{mV} \mathrm{dec}^{-1}\right)\end{array}$ & $\begin{array}{c}\mathrm{I}_{\text {corr }} \\
\left(\mu \mathrm{A} \mathrm{cm} \mathrm{cm}^{-2}\right)\end{array}$ & $\begin{array}{c}\mathrm{E}_{\mathrm{I}} \\
(\%)\end{array}$ \\
\hline Blank & - & 1379 & 34 & -725 & 654 & 133 & 142 & - \\
\hline & $10^{-3}$ & 1437 & 4 & -151 & 1286 & 194 & 13 & 91 \\
\hline \multirow{2}{*}{ L-Cyst } & $10^{-4}$ & 1441 & 5 & -275 & 1166 & 185 & 19 & 87 \\
\cline { 2 - 11 } & $10^{-5}$ & 1378 & 6 & -312 & 1066 & 194 & 36 & 75 \\
\hline & $10^{-6}$ & 1412 & 23 & -429 & 983 & 198 & 67 & 53 \\
\hline
\end{tabular}

3.3.2. Cyclic voltammetry measurements cyclic potentiodynamic polarization

Cyclic voltammetry technic was performed in the solution in the absence and presence of the inhibitor, with the potential (E) swept linearly from $-1.8 \mathrm{~V} / \mathrm{SCE}$

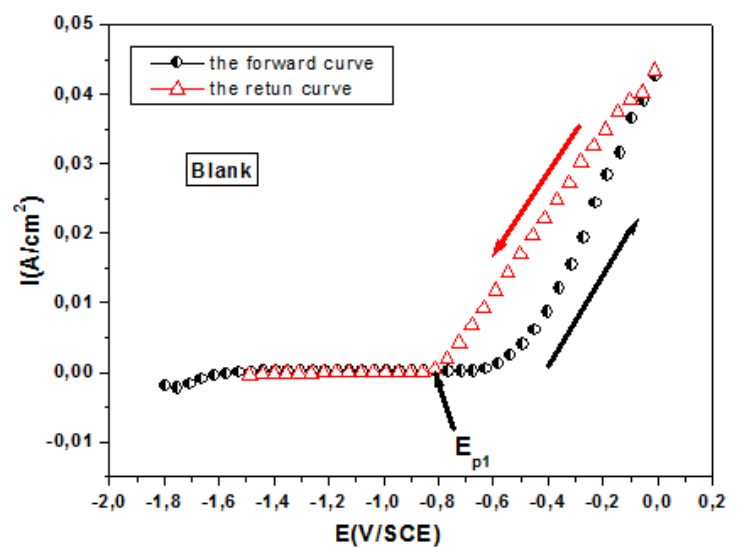

to $+0 \mathrm{~V} / \mathrm{SCE}$ at a sweep rate of $1 \mathrm{mV} \cdot \mathrm{s}^{-1}$. Figure 4 illustrates the cyclic voltammetry curves of aluminum alloy in $\mathrm{Na}_{2} \mathrm{CO}_{3} \quad 0.1 \mathrm{M}+\mathrm{NaCl} 1 \mathrm{M}$ medium with and without inhibitor.

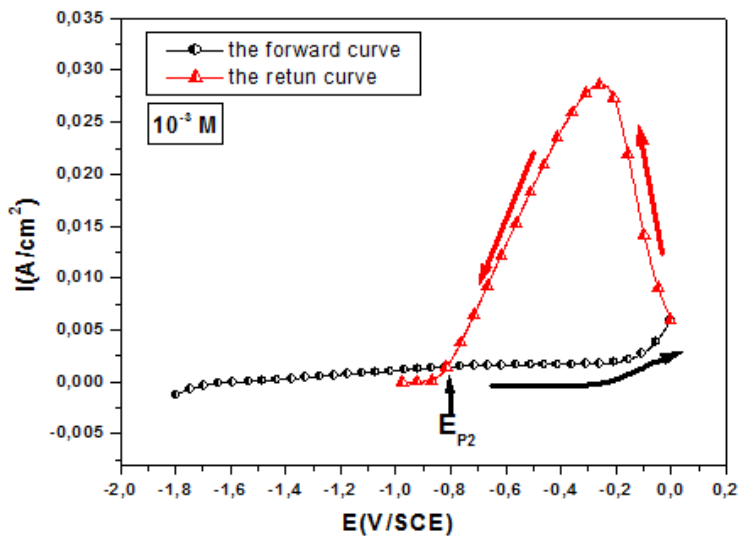

Figure 4. Cyclic voltammetry curves for $\mathrm{AA} 3003$ in $\mathrm{Na}_{2} \mathrm{CO}_{3} 0.1 \mathrm{M}+\mathrm{NaCl} 1 \mathrm{M}$ solution in the presence and absence of L-Cyst at $\mathrm{pH}=11$ and $\mathrm{T}=298 \mathrm{~K}$

The aluminum alloy presents a passivation phenomenon with a breakdown of passivity (Figure 4) in L-Cyst inhibitor's absence and presence. It is clear from Figure 4 that the pitting potential $\mathrm{E}_{\text {pit }}$ is modified by addition of the concentration of the inhibitor; in fact, this addition causes a displacement of $\mathrm{E}_{\mathrm{pit}}$ towards the noblest values and the passive current density $I_{\text {pass }}$ decreases with increasing inhibitor concentration.

\subsubsection{Electrochemical Impedance Spectroscopy measurements}

Figure 5 represents the Nyquist plots for AA3003 in the absence and presence of L-Cyst in $\mathrm{Na}_{2} \mathrm{CO}_{3}$ $0.1 \mathrm{M}+\mathrm{NaCl} 1 \mathrm{M}$ at $298 \mathrm{~K}$. It can be observed that all the impedance spectra obtained display one single depressed semicircle, which indicates that the corrosion process is related to the charge transfer process 34,35 . The depression in Nyquist semicircles may be due to frequency dispersion, inhomogeneities, and roughness of the metal surface and substance transmission actions ${ }^{36,37}$. The similarity in the shapes of Nyquist plots in the absence and presence of inhibitor reveals that the corrosion mechanism is unaffected by the L-Cyst addition. Furthermore, the diameter of the semicircles in L-Cyst's presence is significantly larger than observed in uninhibited solution and increases with increasing inhibitor concentration, which may be due to the formation of protective film on aluminum alloy surface and consequently reduction in corrosion rate ${ }^{38}$.

Accordingly, the EIS data are simulated by the proposed equivalent circuit presented in Figure $5^{39}$. Rs, the solution resistance, Rct denotes the chargetransfer resistance and $\mathrm{CPE}$ is a constant phase element. The introduction of CPE into the circuit was necessitated to explain the depression of the capacitance semicircle, which corresponds to surface heterogeneity resulting from surface roughness, impurities, and adsorption of inhibitors. The impedance parameters obtained are reported in Table 2. It has been seen that $R_{c t}$ increased with an increase in inhibitor concentrations. This can be attributed to the formation of an isolating protective film at the metal/solution interface ${ }^{40}$. The CPE impedance is calculated using the Equation (2): 


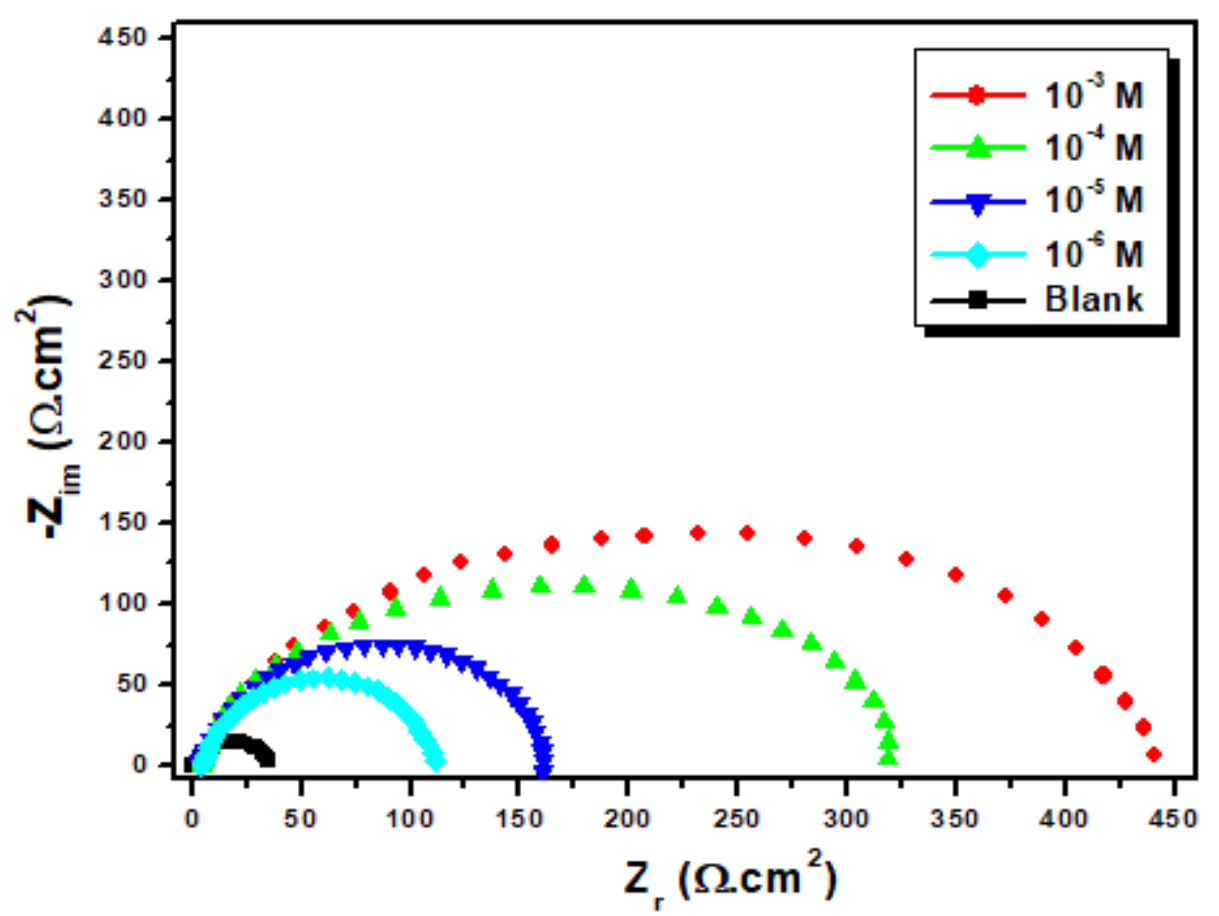

Figure 5. Nyquist plots for $\mathrm{AA} 3003$ in $\mathrm{Na}_{2} \mathrm{CO}_{3} 0.1 \mathrm{M}+\mathrm{NaCl} 1 \mathrm{M}$ containing different concentrations of L-Cyst

$$
Z_{C P E}=\frac{1}{Q \cdot(J \omega)^{n}}
$$

Where $\mathrm{Q}$ is the $\mathrm{CPE}$ constant (in $\Omega^{-1} \times \mathrm{Sn} \times \mathrm{cm}^{-2}$ ), $\omega$ is the angular frequency (in $\mathrm{rad}^{-1} \mathrm{~s}^{-1}, j^{2}=-1$ is the imaginary number, and $n$ is a CPE exponent which can be used as a gauge for the heterogeneity or roughness of the surface. In addition, the double layer capacitances, $C_{\mathrm{dl}}$, for a circuit including a CPE were calculated by using the following Equation (3) ${ }^{41}$ :

$C_{d l}=\sqrt[n]{\mathbf{Q} \cdot \mathbf{R}_{\mathrm{t}}^{1-\mathrm{n}}}$

The inhibition efficiency is calculated from the $R_{c t}$ values using the following Equation (4):

$\mathbf{E}_{\mathbf{R c t}} \%=\frac{\left(\mathbf{R}_{\mathbf{c t}}^{\prime}-\mathbf{R}_{\mathrm{ct}}\right)}{\mathbf{R}_{\mathbf{c t}}^{\prime}} \times \mathbf{1 0 0}$
Where $R_{c t}$ and $R_{c t}^{\prime}$ are the charge transfer resistance values without and with inhibitor, respectively.

The corrosion of aluminum alloy in $\mathrm{Na}_{2} \mathrm{CO}_{3}$ $0.1 \mathrm{M}+\mathrm{NaCl} 1 \mathrm{M}$ is clearly inhibited in the inhibitor's presence and the impedance response change with the increase in inhibitor concentration. The quantitative analysis of electrochemical impedance (EIS) spectra was studied on the basis of a physical model characterizing the charge transfer process at the metal/solution interface. The simplest model includes the charge transfer resistance $\left(\mathrm{R}_{\mathrm{ct}}\right)$ in parallel to the capacitance $\left(\mathrm{C}_{\mathrm{dl}}\right)$ connected with the solution resistance $\left(\mathrm{R}_{\mathrm{s}}\right)$ (Figure 6$)$. The experimental and theoretical results are in good agreement according to the feting carried out by Zview (Figure 7).

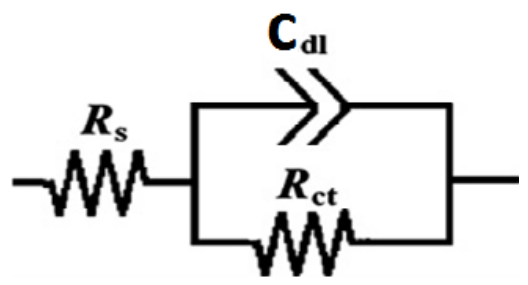

Figure 6. Equivalent electrical circuit corresponding to the corrosion process on aluminum alloy in $\mathrm{Na}_{2} \mathrm{CO}_{3}$

$0.1 \mathrm{M}+\mathrm{NaCl} 1 \mathrm{M}$ 

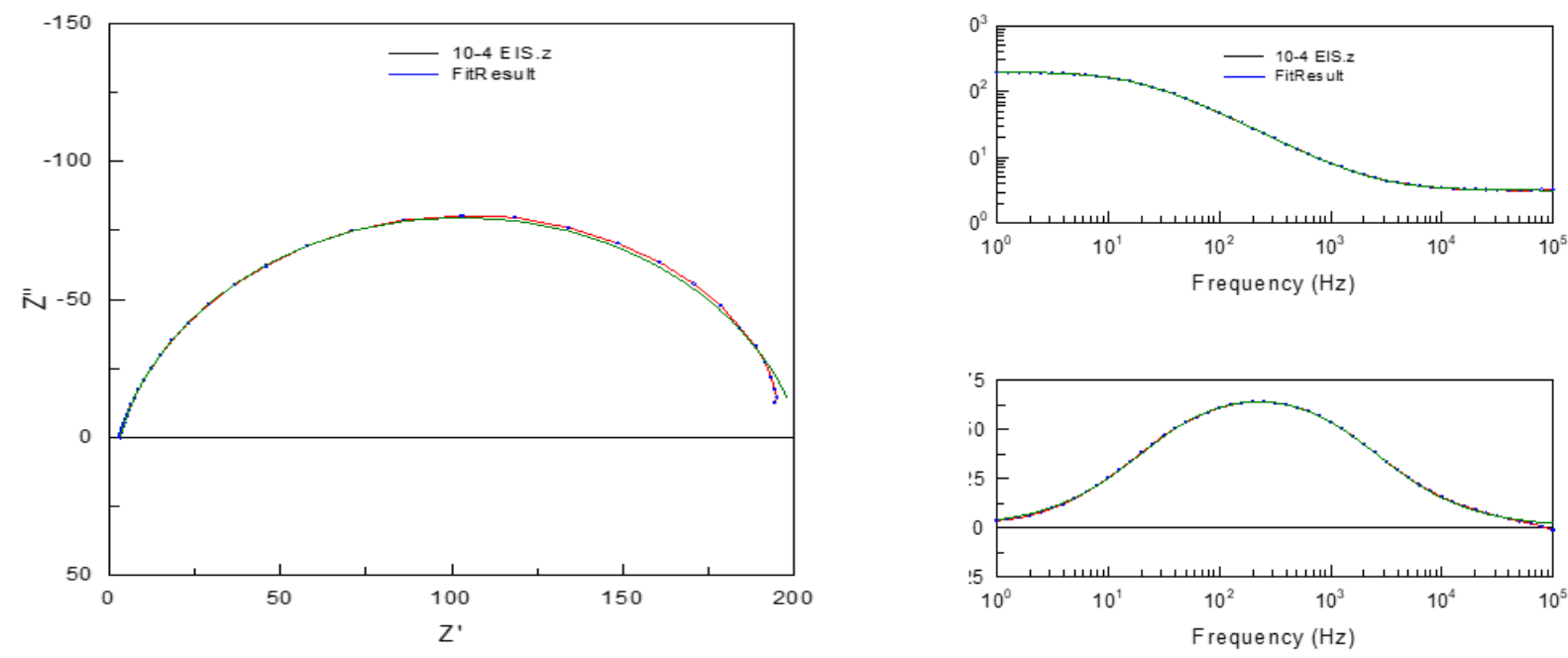

Figure 7. EIS Nyquist and Bode plots for AA3003 in $\mathrm{Na}_{2} \mathrm{CO}_{3} 0.1 \mathrm{M}+\mathrm{NaCl} 1 \mathrm{M}$ of L-Cyt

Table 2. Electrochemical Impedance Spectroscopy for corrosion of aluminum alloy in $\mathrm{Na}_{2} \mathrm{CO}_{3} 0.1 \mathrm{M}+\mathrm{NaCl} 1 \mathrm{M}$ at various concentrations of L-Cyst.

\begin{tabular}{|c|c|c|c|c|c|c|c|}
\hline & $\begin{array}{c}\text { Concentration } \\
\text { (M) }\end{array}$ & $\begin{array}{c}\boldsymbol{R}_{\mathrm{ct}} \\
\left(\mathbf{\Omega} \times \mathbf{c m}^{2}\right)\end{array}$ & $n$ & 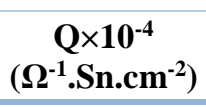 & $\begin{array}{c}\mathbf{C}_{\mathrm{dl}} \\
\left(\mu \mathbf{F} / \mathbf{c m}^{2}\right)\end{array}$ & $\begin{array}{l}E_{\text {Rct }} \\
(\boldsymbol{\%})\end{array}$ & $\boldsymbol{\theta}$ \\
\hline Blank & - & 35 & 0.85 & 0.16 & 4,37 & - & - \\
\hline \multirow{4}{*}{ L-Cyst } & $10^{-3}$ & 437.5 & 0.76 & 0.304 & 8 & 92 & 0.92 \\
\hline & $10^{-4}$ & 318 & 0.74 & 0.480 & 11 & 89 & 0.823 \\
\hline & $10^{-5}$ & 196 & 0.75 & 0.863 & 22 & 78 & 0.734 \\
\hline & $10^{-6}$ & 11 & 0.78 & 1.42 & 44 & 56 & 0.562 \\
\hline
\end{tabular}

Table 2 shows that the charge transfer resistance (Rct) increases with the increase of inhibitor concentration. However, double layer capacitance (Cdl) decreases because it depends inversely of charge transfer resistance in all concentrations. This result may be attributed to forming a protective layer on the electrode surface ${ }^{42}$.

The results show that the L-Cyst inhibits the corrosion of aluminum alloy in $\mathrm{Na} 2 \mathrm{CO} 3 \quad 0.1 \mathrm{M}+\mathrm{NaCl} 1 \mathrm{M}$ solution at different concentrations studied. The efficiency increases with the rise of concentration at 298K (Table 2). The $\mathrm{I}_{\mathrm{E}}(\%)$ obtained from EIS techniques and those calculated from polarization curves are in good agreement.

\subsubsection{Adsorption isotherm and thermodynamic parameters}

An inhibitor's action in the alkaline medium is assumed to be due to its adsorption to the metal/solution interface. The kind of adsorption isotherm can give more information about the properties of the studied extracts. Several adsorption isotherms were tested, and the Langmuir adsorption isotherm was found to furnish the best description of the studied organic compound's adsorption behavior. The Langmuir isotherm is given by the following Equation $^{43}$ :

$\frac{\mathrm{C}_{\mathrm{inh}}}{\theta}=\frac{1}{\mathrm{~K}_{\mathrm{ads}}}+\mathrm{C}_{\mathrm{inh}}$

Where $\theta$ is the surface coverage, $K_{a d s}$ is the adsorption-desorption equilibrium constant, $\mathrm{C}_{\mathrm{inh}}$ is the concentration of inhibitor.

Figure 8 shows $C_{\text {inh }} / \theta$ versus $C_{\text {inh }}$ and the expected linear relationship is obtained for this compound. The strong correlation $\left(\mathrm{R}^{2}=0.9999\right.$ for the compound $\mathrm{L}$ Cyst) confirms the validity of this approach. The thermodynamic parameters from the Langmuir adsorption isotherm are listed in Table 3, together with the value of the Gibbs free energy of adsorption $\Delta \mathrm{G}_{\text {ads }}^{0}$ calculated from the Equation:

$\Delta \mathbf{G}_{\mathrm{ads}}^{0}=-\mathrm{RT} \ln \left(55,5 \times \mathrm{K}_{\mathrm{ads}}\right)$

Where 55.5 is the concentration of water, $\mathrm{R}$

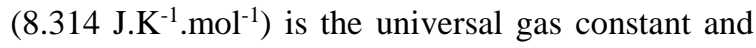
$\mathrm{T}$ is the absolute temperature $(\mathrm{K}), \mathrm{K}_{\mathrm{ads}}$ the adsorptiondesorption equilibrium constant ${ }^{44}$. 


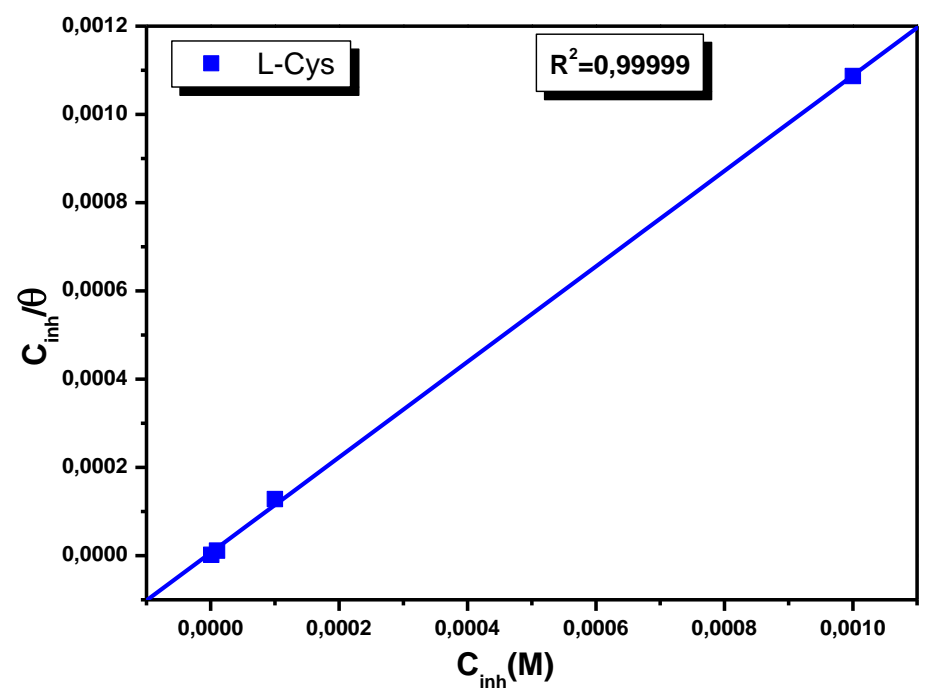

Figure 8. Langmuir adsorption of inhibitor on the aluminum surface in $0.1 \mathrm{M} \mathrm{Na}_{2} \mathrm{CO}_{3}+\mathrm{NaCl} 1 \mathrm{M}$ solution at $298 \mathrm{~K}$

Table 3. Adsorption parameters of inhibitor for aluminum alloy in $0.1 \mathrm{M} \mathrm{Na}_{2} \mathrm{CO}_{3}+\mathrm{NaCl} 1 \mathrm{M}$ solution at $298 \mathrm{~K}$.

\begin{tabular}{|c|c|c|c|c|}
\hline Inhibitor & Slope & $\mathbf{K}_{\text {ads }}\left(\mathbf{M}^{-1}\right)$ & $\mathbf{R}^{2}$ & $\Delta G_{\text {ads }}^{\circ}(\mathbf{k J} / \mathbf{m o l})$ \\
\hline L-Cyst & 1.1444 & $\mathbf{5 6 4 9 7 1 . 7 5}$ & $\mathbf{0 . 9 9 9 9}$ & $\mathbf{- 4 2 . 7 4}$ \\
\hline
\end{tabular}

The $\Delta \mathrm{G}_{\text {ads }}^{0}$ value is calculated as $-42.74 \mathrm{~kJ} . \mathrm{mol}^{-1}$ for L-Cyst. In the literature, if the absolute values of $\Delta \mathrm{G}_{\text {ads }}^{0}$ are less than $20 \mathrm{~kJ}^{\mathrm{mol}}{ }^{-1}$ consistent with the electrostatic interaction between the charged metal and charged molecules (physisorption). But if those more than $40 \mathrm{~kJ} \mathrm{~mol}^{-1}$ involve sharing or transferring electrons from the inhibitor compound to the metal surface to form a coordinate type of bond (chemisorption) ${ }^{45,46}$. The standard adsorption free energy value shown in Table 3 suggests that adsorption is chemisorption.

\subsection{Effect of temperature}

The effect of temperature on the corrosion rate of aluminum alloy in $0.1 \mathrm{M} \mathrm{Na}_{2} \mathrm{CO}_{3}+\mathrm{NaCl} 1 \mathrm{M}$ with the addition of the L-Cyst inhibitor is made from 298 to $328 \mathrm{~K}$ shown in Table 4 using electrochemical

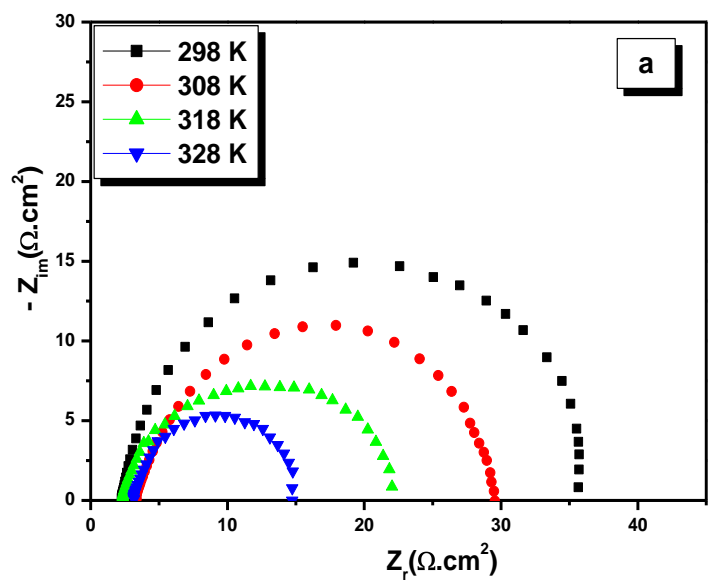

impedance spectroscopy measurements technique. $R_{\mathrm{ct}}$ decrease with increasing temperature both in uninhibited and inhibited solutions, and the efficiency of inhibition by L-Cyst decreases slightly with increasing temperature. The results confirm that the L-Cyst acts as an efficient inhibitor in the range of temperature studied.

On the other hand, the values of $\mathrm{R}_{\mathrm{ct}}$ were employed to calculate values of the corrosion current density $\left(\mathrm{I}_{\text {corr }}\right)$ at various temperatures in the absence and presence of L-Cyst using the following Equation ${ }^{47}$ :

$$
I_{c o r r}=\boldsymbol{R} . \boldsymbol{T}\left(\boldsymbol{Z} \cdot \boldsymbol{F} \cdot \boldsymbol{R}_{c t}\right)^{-1}
$$

$\mathrm{R}$ is the universal gas constant, $\mathrm{T}$ is the absolute temperature, $\mathrm{z}$ is the valence of Aluminum $(\mathrm{z}=3), \mathrm{F}$ is the Faraday constant $\left(F=96485\right.$ Coulomb) $R_{c t}$ is the charge transfer resistance.

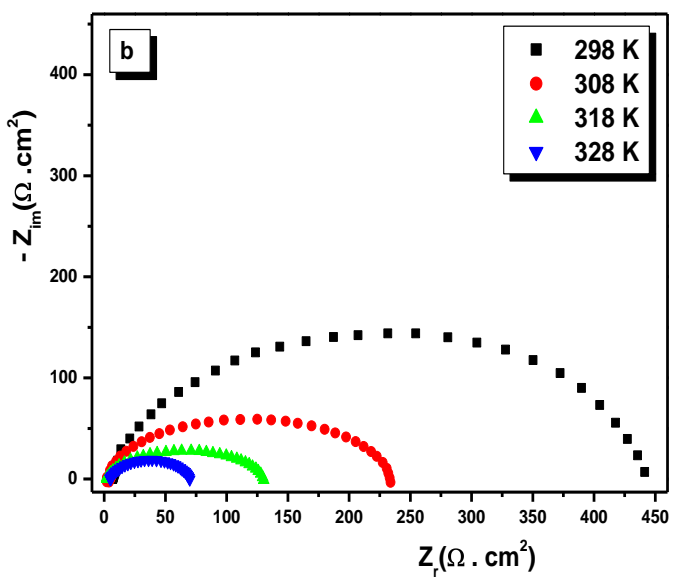

Figure 9. Nyquist plots for corrosion aluminum alloy in $0.1 \mathrm{M} \mathrm{Na}_{2} \mathrm{CO}_{3}+\mathrm{NaCl} 1 \mathrm{M}$ (a) and $10^{-3} \mathrm{M}$ of L-Cyst (b) at different temperatures 
Table 4. Effect of temperature on the aluminum alloy corrosion in $0.1 \mathrm{M} \mathrm{Na}_{2} \mathrm{CO}_{3}+\mathrm{NaCl}_{1 \mathrm{M}}$ and at $10^{-3} \mathrm{M}$ of $\mathrm{L}-$ Cyst.

\begin{tabular}{|c|c|c|c|c|c|c|c|}
\hline & $\begin{array}{c}\text { Temperature } \\
(\mathrm{K})\end{array}$ & $\begin{array}{c}R_{\mathrm{ct}} \\
\left(\Omega \times \mathrm{cm}^{2}\right)\end{array}$ & $n$ & $\begin{array}{c}\mathrm{Q} \times 10^{-4} \\
\left(\Omega^{-1} \cdot \mathrm{Sn} \cdot \mathrm{cm}^{-2}\right)\end{array}$ & $\begin{array}{c}\mathrm{C}_{\mathrm{dl}} \\
\left(\mu \mathrm{F} / \mathrm{cm}^{2}\right)\end{array}$ & $\begin{array}{l}\eta_{\mathrm{EIS}} \\
(\%)\end{array}$ & $\Theta$ \\
\hline \multirow{4}{*}{ Blank } & 298 & 35 & 0.89 & 0.39 & 101 & - & - \\
\hline & 308 & 28 & 0.87 & 0.54 & 57 & - & - \\
\hline & 318 & 22 & 0.85 & 0.79 & 48 & - & - \\
\hline & 328 & 14 & 0.84 & 0.98 & 38 & - & - \\
\hline \multirow{4}{*}{$\begin{array}{c}\text { L-Cyst } \\
10^{-3} \mathrm{M}\end{array}$} & 298 & 437,5 & 0.76 & 0.304 & 8 & 92 & 0.92 \\
\hline & 308 & 233 & 0.77 & 0.312 & 7 & 88 & 0.88 \\
\hline & 318 & 129 & 0.74 & 0.482 & 8 & 83 & 0.83 \\
\hline & 328 & 70 & 0.72 & 0.655 & 7.5 & 80 & 0.80 \\
\hline
\end{tabular}

The logarithm of the corrosion rate of aluminum alloy $\mathrm{I}_{\text {corr }}$ can be represented as a straight-line function of 1000/T (Arrhenius equation, Figures 12-13).

$I_{c o r r}=A \cdot \exp \left(-\frac{E_{a}}{R T}\right)$

Where $\mathrm{A}$ is Arrhenius factor, $\mathrm{E}_{\mathrm{a}}$ is the apparent activation corrosion energy $((\mathrm{J} / \mathrm{mol}), \mathrm{R}$ is the perfect gas constant $\left(8.314 \mathrm{~J} \cdot \mathrm{K}^{-1} \cdot \mathrm{mol}^{-1}\right)$, and $\mathrm{T}$ the absolute temperature $(\mathrm{K})$.

The value of $E_{a}$ can be calculated from the slope of the straight line of Arrhenius plots. The higher value of $E_{a}$ in L-Cyst's presence than its absence indicates strong inhibitive action of the organic compound by increasing the energy barrier for the corrosion process $^{48}$.

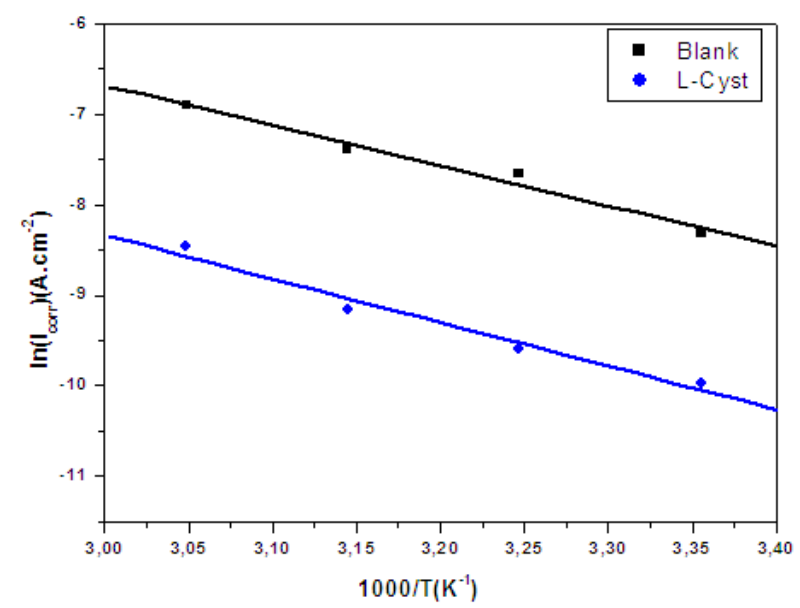

Figure 10. Arrhenius plots of aluminum corrosion in $0.1 \mathrm{M} \mathrm{Na}_{2} \mathrm{CO}_{3}+\mathrm{NaCl} 1 \mathrm{M}$ with and without inhibitor $\left(10^{-3} \mathrm{M}\right)$
However, the adsorption phenomenon has been successfully explained by thermodynamic parameters. To elucidate the inhibitors' properties further, the kinetic model was another useful tool to explain the mechanism of corrosion inhibition for the inhibitor. The activation parameters for the corrosion process were calculated from the Arrhenius equation:

$I_{c o r r}=\frac{R T}{N h} \cdot \exp \left(\frac{\Delta S_{a}}{R T}\right) \cdot \exp \left(-\frac{\Delta H_{a}}{R T}\right)$

Where $\mathrm{h}$ is Planck's constant, $\mathrm{N}$ Avogadro's number $\left(\mathrm{mol}^{-1}\right), \mathrm{R}$ the universal gas constant, $\Delta \mathrm{H}_{\mathrm{a}}$ the activation enthalpy $(\mathrm{J} / \mathrm{mol})$, and $\Delta \mathrm{S}_{\mathrm{a}}$ is the activation entropy $(\mathrm{J} / \mathrm{mol})$.

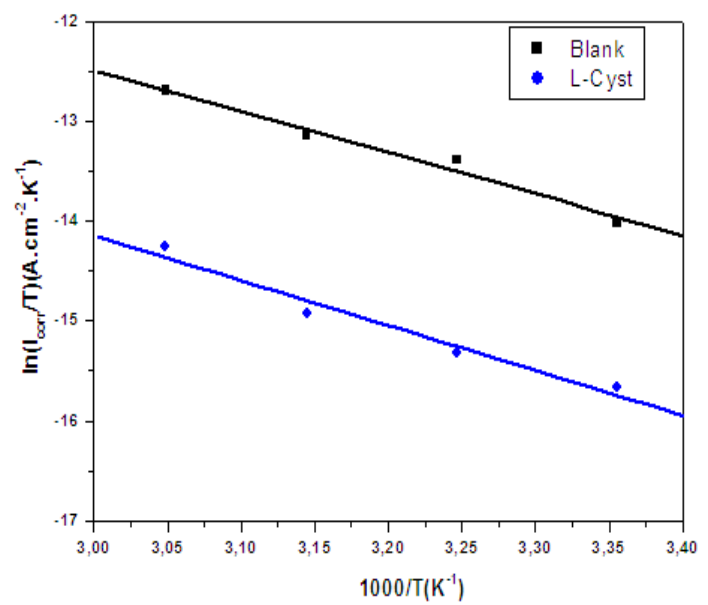

Figure 11. Relation between $\operatorname{Ln}\left(\mathrm{I}_{\text {corr }} / \mathrm{T}\right)$ and $1000 / \mathrm{T}$ at different temperatures $\left(10^{-3} \mathrm{M}\right)$

Table 5. The value of activation parameters $E_{a}, \Delta H_{a}$ and $\Delta S_{a}$ for $A A 3003$ in $0.1 \mathrm{M} \mathrm{Na}_{2} \mathrm{CO}_{3}+\mathrm{NaCl} 1 \mathrm{M}$ in the absence and presence of L-Cyst at $10^{-3} \mathrm{M}$.

\begin{tabular}{|c|c|c|c|c|}
\hline Inhibitor & $\Delta \mathbf{H}_{\mathbf{a}}(\mathbf{k J} / \mathbf{m o l})$ & $\Delta \mathbf{S}_{\mathbf{a}}(\mathbf{J} / \mathbf{m o l})$ & $\mathbf{E}_{\mathbf{a}}(\mathrm{kJ} / \mathbf{m o l})$ & $\mathbf{E a}-\Delta \mathbf{H}_{\mathbf{a}}$ \\
\hline Blank & $\mathbf{2 4 . 1 5}$ & $\mathbf{- 2 2 9 . 9 3}$ & $\mathbf{2 6 . 7 5}$ & $\mathbf{2 . 6 0}$ \\
\hline L-Cyst & $\mathbf{3 7 . 4 3}$ & $\mathbf{- 2 1 0 . 4 5}$ & $\mathbf{3 9 . 8 7}$ & $\mathbf{2 . 6 0}$ \\
\hline
\end{tabular}


The increase of $\Delta \mathrm{S}_{\mathrm{a}}$ is usually interpreted as an increase in disorder as the reactants are converted to the activated complexes ${ }^{44}$. From Table 5 , we note that a less harmful value of $\Delta \mathrm{S}_{\mathrm{a}}$ is obtained in the presence of L-Cyst, while a more negative value is observed in the uninhibited solution. The values of $\Delta \mathrm{S}_{\mathrm{a}}$ calculated in the fact of inhibitor decrease compared with the blank solution. This result is interpreted as an increase in disorder ${ }^{47}$.

The difference between the two values is almost constant with an average value of $2.60 \mathrm{~kJ} \mathrm{~mol}^{-1}$ which is very close to the average value of the product (RT) in the investigated temperature range. Such behavior is characteristic of a unimolecular gas-phase reaction obeying the following Equation $^{49}$ :

$E_{a}-\Delta H_{a}=R T$

\subsection{SEM studies}

SEM technique was employed to prove L-Cyst's corrosion resistance ability further, and the surface observation images of the aluminum alloy after a 20 days exposure in $0.1 \mathrm{M} \mathrm{Na}_{2} \mathrm{CO}_{3}+\mathrm{NaCl} 1 \mathrm{M}$ solution without and with inhibitor are shown in Figure 6. Before immersion, the bare aluminum plate looks very smooth (Figure 12a). In contrast, in the absence of an inhibitor, the AA3003 presented a very rough surface covered with a vast amount of deep cracks and large holes, suggesting severe damage and painful dissolution of aluminum alloy in contact with an aggressive solution (Figure 12b). Nevertheless, in Figure 12c, aluminum alloy's dissolution rate was substantially inhibited by L-Cyst, exhibiting a comparatively smooth surface with a few small pits. Therefore, it is concluded that the regular distribution of the L-Cyst. Consequently, it is concluded that the regular distribution of L-Cyst molecules adsorbed on the AA3003 surface generates coherent protective layers, which effectively prevent $\mathrm{Cl}^{-}$ions from penetrating.
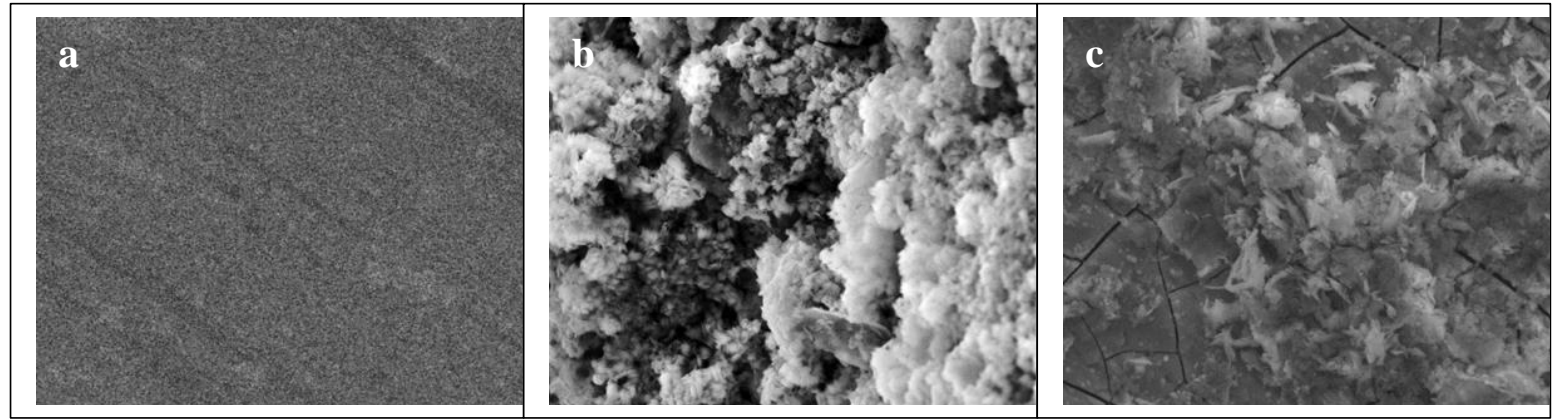

\subsection{DFT Calculation results}

The quantum chemical calculations are used to make sure the relationship between the inhibition effect of the synthesized inhibitor and its molecular structures.
The optimized molecular structure and the frontier molecular orbitals density distributions are shown in Figure 13. The quantum chemical parameters are regrouped in Table 6 .

Table 6. Calculated quantum chemical parameters of the inhibitor molecule.

\begin{tabular}{|c|c|c|c|c|c|c|c|c|}
\hline Model & $\begin{array}{c}\mathrm{E}_{\text {HOMO }} \\
(\mathrm{eV})\end{array}$ & $\begin{array}{c}\mathrm{E}_{\text {LUMO }} \\
(\mathrm{eV})\end{array}$ & $\begin{array}{c}\Delta \mathrm{E} \\
(\mathrm{eV})\end{array}$ & $\begin{array}{c}\mu \\
(\mathrm{D})\end{array}$ & $\begin{array}{c}\eta \\
(\mathrm{eV})\end{array}$ & $\begin{array}{c}\sigma \\
\left(\mathrm{eV}^{-1}\right)\end{array}$ & $\begin{array}{c}\chi \\
(\mathrm{eV})\end{array}$ & $\Delta \mathrm{N}$ \\
\hline B3LYP & $\mathbf{- 6 . 5 3 0}$ & $\mathbf{- 0 . 1 7 0}$ & $\mathbf{6 . 3 6 0}$ & $\mathbf{4 . 9 3 2}$ & $\mathbf{3 . 1 8 0}$ & $\mathbf{0 . 3 1 4}$ & $\mathbf{3 . 3 5 0}$ & $\mathbf{0 . 1 5}$ \\
\hline
\end{tabular}

According to Koopman's theorem ${ }^{50}$, the energies of HOMO and LUMO are correlated to the ionization potential (I) and the electron affinity (A), respectively, which defined as follows:

$\mathrm{I}=-\mathrm{E}_{\text {НОмо }}$

$\mathrm{A}=-\mathrm{E}_{\mathrm{LUMO}}$

The energy gap is determined as follow:

$\Delta \mathrm{E}=\mathrm{E}_{\text {LUMO }}-\mathrm{E}_{\mathrm{HOMO}}$

The values of I and A were considered for the calculation of the electronegativity $\chi$ and the global hardness $\eta$ was determined using the following equations:

$\chi=\frac{I+A}{2}$
$\eta=\frac{I-A}{2}$

The fraction of electrons transferred from inhibitor to metal surface $(\Delta N)$ was estimated according to Pearson ${ }^{51}$.

$\Delta N=\frac{\chi_{M}-\chi_{i n h}}{2 .\left(\eta_{M}+\eta_{i n h}\right)}=\frac{\phi_{M}-\chi_{i n h}}{2 \eta_{i n h}}$

Where $\left(\chi_{M}, \eta_{M}\right)$ and $\left(\chi_{\text {inh }}, \eta_{\text {inh }}\right)$ are, respectively, the electronegativity and hardness of the metal and the inhibitor when $\phi_{\mathrm{M}}$ is the work function. In our study, the theoretical values of electronegativity $\phi_{\mathrm{Al}}=4.28 \mathrm{eV}^{51}$ and hardness $\eta_{\mathrm{Al}}=0^{52}$ have been used for Aluminum.

Generally, the inhibition efficiency increases with the increase in electron-donating ability to the metal surface. 
According to Lukovits's study, this is true if $\Delta \mathrm{N}<3.6^{53}$. Based on these calculations, we can say that our inhibitor favors chemical adsorption on the aluminum alloy surface.

In this paper, the HOMO and LUMO orbital energies were calculated by using the B3LYP method with 6-31G. All other calculations were performed using the results with some assumptions. The higher values of $\mathrm{E}_{\text {номо }}$ indicate an increase for the electron donor, which means a better inhibitory activity with increasing adsorption of the inhibitor on a metal surface. In contrast, $\mathrm{E}_{\mathrm{Lumo}}$ suggests the ability to accept the electron of the molecule. The inhibitor's adsorption ability to the metal surface increases with the increasing of $\mathrm{E}_{\mathrm{HOMO}}$ and decreasing of $\mathrm{E}_{\mathrm{LUMO}}$.
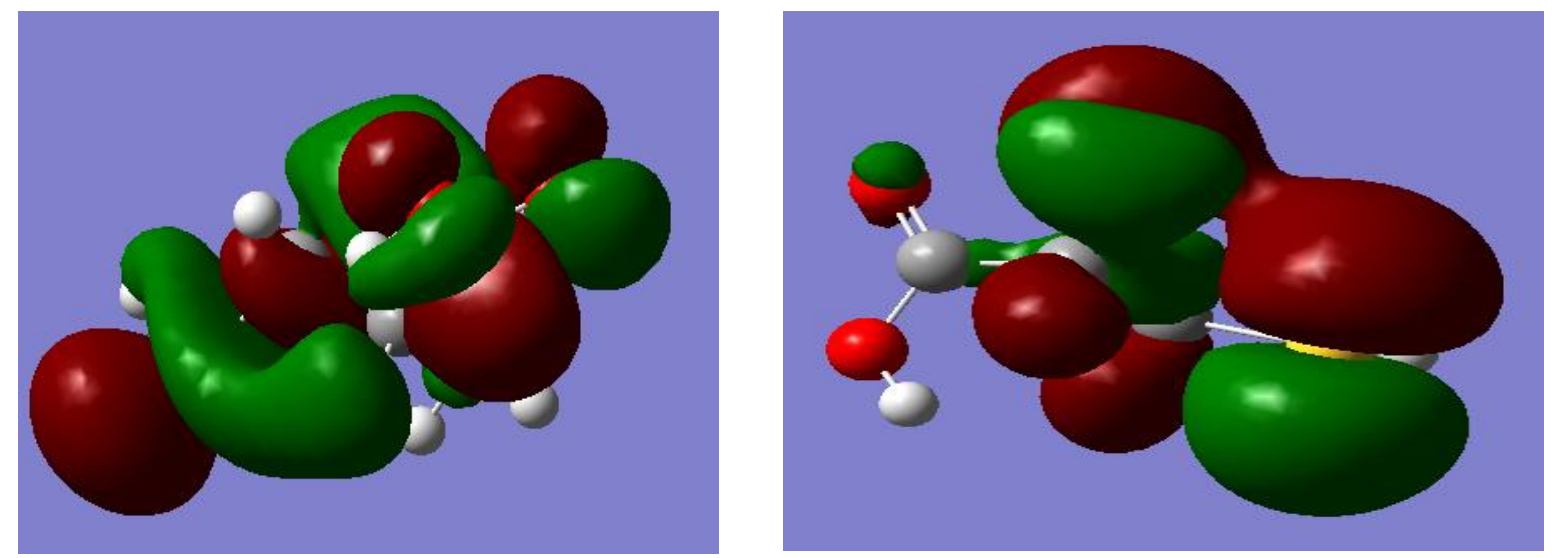

Figure 13. The frontier molecular orbital density distribution of L-Cyst (left, LUMO; right, HOMO)

\section{Conclusion}

The organic compound L-Cyst as corrosion inhibitor for aluminum alloy in a $0.1 \mathrm{M} \mathrm{Na}_{2} \mathrm{CO}_{3}+\mathrm{NaCl} 1 \mathrm{M}$ solution was investigated. Through the results from our experimental study, we quote the following conclusions:

- For L-Cyst, their inhibition efficiency increased with increases in inhibitor concentration, and they belonged to mixedtype inhibitor predominantly retarding the cathodic reaction.

- The inhibiting efficiencies determined by methods potentiodynamic polarization testing and EIS measurements are all in good agreement.

- The adsorption processes of L-Cyst molecules followed the Langmuir adsorption isotherm. The calculated $\Delta \mathrm{G}^{\circ}$ ads values indicated that this inhibitor was spontaneously absorbed on the aluminum alloy surface and was more inclined to a chemisorption mechanism at $298 \mathrm{~K}$.

- The surface morphologies images were suitable proof for reducing the dissolution of aluminum alloy ascribed to the formation of protective L-Cyst film on the metal surface.

\section{References}

1- M. Dabalà, E. Ramous, M. Magrini, Corrosion resistance of cerium-based chemical conversion coatings on AA5083 aluminium alloy, Mater. Corros., 2004, 55, 381-386.
2- A. Y. Musa, A. A. H. Kadhum, A. B. Mohamad, M. S. Takriff, A. R. Daud, S. K. Kamarudin, On the inhibition of mild steel corrosion by 4 -amino5-phenyl-4H-1, 2, 4-trizole-3-thiol, Corros. Sci., 2010, 52, 526-533.

3- R. Rosliza, W. B. W. Nik, S. Izman, Y. Prawoto, Anti-corrosive properties of natural honey on Al$\mathrm{Mg}-\mathrm{Si}$ alloy in seawater, Curr. Appl. Phys., 2010, 10, 923-929.

4- J. A. Hill, T. Markley, M. Forsyth, P. C. Howlett, B. R. W. Hinton, Corrosion inhibition of 7000 series aluminium alloys with cerium diphenyl phosphate, J. Alloy. Compd., 2011, 509, 1683-1690.

5- R. Rosliza, W. B. W. Nik, H. B. Senin, The effect of inhibitor on the corrosion of aluminum alloys in acidic solutions, Mater. Chem. Phys., 2008, 107, 281-288.

6- S. Gudić, L. Vrsalović, M. Kliškić, I. Jerković, A. Radonić, M. Zekić, Corrosion Inhibition of AA 5052 Aluminium Alloy in $\mathrm{NaCl}$ Solution by Different Types of Honey, Int. J. Electrochem. Sci., 2016, 11, 998-1011.

7- E. E. Oguzie, G. N. Onuoha, E. N. Ejike, Effect of Gongronema latifolium extract on aluminium corrosion in acidic and alkaline media, Pigment Resin Technol., 2007, 36, 44-49.

8. A. M. Al-Turkustani, S. T. Arab, R. H. Al-Dahiri, Aloe Plant Extract as Environmentally Friendly Inhibitor on the Corrosion of Aluminum in Hydrochloric Acid in Absence and Presence of Iodide Ions, Mod. Appl. Sci., 2010, 4, 105-124.

9- J. Li, B. Hurley, R. Buchheit, Micro electrochemical Characterization of the Effect of Rare Earth Inhibitors on the Localized Corrosion 
of AA2024-T3, J. Electrochem. Soc., 2015, 162, C563-C571.

10-G. O. Ilevbare, J. R. Scully, Mass-TransportLimited Oxygen Reduction Reaction on AA2024-T3 and Selected Intermetallic Compounds in Chromate-Containing Solutions, Corrosion, 2001, 57, 134-152.

11-X. Li, S. Deng, Inhibition effect of Dendrocalamus brandisii leaves extract on Aluminum in $\mathrm{HCl}, \mathrm{H}_{3} \mathrm{PO}_{4}$ solutions, Corros. Sci., 2012, 65, 299-308.

12-S. M. A. Hosseini, A. Azimi, The inhibition of mild steel corrosion in acidic medium by 1-methyl-3-pyridin-2-yl-thiourea, Corros. Sci., 2009, 51, 728-732.

13-C. M. Goulart, A. Esteves-Souza, C. A. Martinez-Huitle, C. J. F. Rodrigues, M. A. M. Maciel, A. chevarria, Experimental and theoretical evaluation of semicarbazones and thiosemicarbazones as organic corrosion inhibitors, Corros. Sci., 2013, 67, 281-291.

14-W. Li, Q. He, C. Pei, B. Hou, Experimental and theoretical investigation of the adsorption behaviour of new triazole derivatives as inhibitors for mild steel corrosion in acid media, Electrochim. Acta, 2007, 52, 6386-6394.

15-F. Bentiss, M. Lagrenee, M. Traisnel, J. C. Hornez, The Corrosion Inhibition of Mild Steel in Acidic Media by a New Triazole Derivative, Corros. Sci., 1999, 41, 789-803.

16-A. M. Fekry, R. R. Mohamed, Acetyl thiourea chitosan as an eco-friendly inhibitor for mild steel in sulphuric acid medium, Electrochim. Acta, 2010, 55, 1933-1939.

17-K. F. Khaled, The inhibition of benzimidazole derivatives on corrosion of iron in $1 \mathrm{M} \mathrm{HCl}$ solutions, Electrochim. Acta, 2003, 48, 2493-2503.

18-K. F. Khaled, Experimental, density function theory calculations and molecular dynamics simulations to investigate the adsorption of some thiourea derivatives on iron surface in nitric acid solutions, Appl. Surf. Sci., 2010, 256, 6753-6763.

19-M. Mehdipour, B. Ramezanzadeh, S. Y. Arman, Electrochemical noise investigation of Aloe plant extract as green inhibitor on the corrosion of stainless steel in $1 \mathrm{M} \mathrm{H}_{2} \mathrm{SO}_{4}$, J. Ind. Eng. Chem., 2015, 21, 318-327.

20-A. M. Abdel-Gaber, B. A. Abd-El-Nabey, I. M. Sidahmed, A. M. El-Zayady, M. Saadawy, Inhibitive action of some plant extracts on the corrosion of steel in acidic media, Corros. Sci., 2006, 48, 2765-2779.

21-E. Azzouyahar, L. Bazzi1, M. Essahli, M. Belkhaouda, A. Lamiri, Nigella Sativa Oil as Green Corrosion Inhibitor for Aluminum in $\mathrm{Na}_{2} \mathrm{CO}_{3}$ Solution, Journal of applicable chemistry, 2014, 4, 1602-1612.

22-K. Barouni, L. Bazzi, R. Salghi, M. Mihit,
B. Hammouti, A. Albourine, S. El Issami, Some amino acids as corrosion inhibitors for copper in nitric acid solution, Materials Letters, 2008, 62, 3325-3327.

23-M. Chadili, M. M. Rguiti, B. El Ibrahimi, R. Oukhrib, A. Jmiai, M. Beelkhaouda, L. Bammou, M. Hilali, L. Bazzi, Corrosion Inhibition of 3003 Aluminum Alloy in Molar Hydrochloric Acid Solution by Olive Oil Mill Liquid By-Product, International Journal of Corrosion, 2021. https://doi.org/10.1155/2021/6662395.

24-R. Salghi, L. Bazzi, B. Hammouti, A. Bouchtart, S. Kertit, Z. A. Ait addi, Z. El alami, Étude électrochimique de l'inhibition de la corrosion de l'alliage d'aluminium 3003 en milieu bicarbonate par les composés triazolique, Ann, Chim, Sci. Mat., 2000, 25, 187-200.

25-K. Shalabi, Y. M. Abdallah, A. S. Fouda, Corrosion inhibition of Aluminum in $0.5 \mathrm{M} \mathrm{HCl}$ solutions containing phenyl sulfonyl acetophenone azo derivatives, Res. Chem. Intermed., 2014, 41, 4687-4711.

26-D. Becke, A new mixing of Hartree-Fock and local density-functional theories, J. Chem. Phy., 1993, 98, 1372.

27-C. Lee, W. Yang, R. G. Parr, Development of the Colic-Salvetti correlation-energy formula into a functional of the electron density, Phy. Rev. B, 1988, 37, 785 .

28-D. Ramirez, R. Vera, H. H. Gomez, C. Conajahua, Evaluation of protecting properties of epoxy coatings on Navy steel by Electrochemical Impedance Spectroscopy, J. Chil. Chem. Soc., 2005, 50, 489-494.

29-L. Bazzi, S. Kertit, M. Hamdani, Effet de l'addition d'oxo-anions sur le comportement à la corrosion de l'alliage d'aluminium 6063 en milieu hydrogénocarbonate, J. Chim. Phys., 1995, 92, 1612-1628.

30-M. Belkhaouda, L. Bazzi, A. Benlhachemi, R. Salghi, B. Hammouti, A. Ihlal, Influence of the heat treatment on the corrosion behaviour of 3003 aluminium alloy in alkaline medium, Phys. Chem. News, 2009, 48, 81-88.

31-L. Bazzi, S. Kertit, M. Hamdani, Effet de l'addition d'ions chromates sur le comportement à la corrosion d'un alliage d'aluminium 6063 en milieu neutre, pollué par les ions cuivriques, J. Chim. Phys., 1997, 94, 93-104.

32-R. Ambat, E. S. Dwarakadasa, The influence of $\mathrm{pH}$ on the corrosion of medium strength aerospace alloys 8090, 2091 and 2014, Corros. Sci., 1992, 33, 681-690.

33-K. R. Ansari, D. K. Yadav, E. E. Ebenso, M. A. Quraishi, Novel and Effective Pyridyl Substituted 1,2,4-Triazole as Corrosion Inhibitor for Mild Steel in Acid Solution, Int. J. Electrochem. Sci., 2012, 7, 4780-4799.

34-K. Toumiat, Y. El Aoufir, H. Lgaz, R. Salghi, 
S. Jodeh, M. Zougagh, Monte Carlo Simulation and Electrochemical Assessment of Inhibitive Behavior of Pyrazole Derivative On Mild Steel in $\mathrm{HCl}$ Medium, Res. J. Pharm. Biol. Chem. Sci., 2016, 7, 1209-1217.

35-S. Kharacha, A. Batah, M. Belkhaouda, L. Bazzi, L. Bammou, R. Salghi, O. Jbara, A. Tara, Effect of amino acid on the passivation, corrosion and inhibition behavior of aluminum alloy in alkaline medium, Mor. J. Chem., 2018, 6, 294-306.

36-O. Krim, S. Jodeh, M. Messali, B. Hammouti, A. Elidrissi, K. Khaled, Synthesis, Characterization and Corrosion Protection Properties of Imidazole Derivatives on Mild Steel in 1.0 M HCl, Port Electrochimica Acta, 2016, 34, 213-229.

37-B. El Makrini, H. Lgaz, K. Toumiat, R. Salghi, S. Jodeh, G. Hanbali, Adsorption and CorrosionInhibiting Effect of 5-Benzyloxy-6methoxyindole on Mild Steel Surface in Hydrochloric Acid Solution: Electrochemical and Monte Carlo simulation studies, Res. J. Pharm. Biol. Chem. Sci., 2016, 7, 2277-2285.

38-B. El Makrini, K. Toumiat, H. Lgaz, R. Salghi, S. Jodeh, G. Hanbali, Corrosion protection of mild steel in hydrochloric acid solutions in presence of 5-(Benzyloxy) indole - Monte Carlo simulation, weight loss and electrochemical studies, Res. J. Pharm. Biol. Chem. Sci., 2016, 7, 2286-2294.

39-N. O. Eddy, H. Momoh-Yahaya, E. E. Oguzie, Theoretical and experimental studies on the corrosion inhibition potentials of some purines for Aluminum in $0.1 \mathrm{M} \mathrm{HCl}, \mathrm{J}$ Adv Res., 2015, 6, 203-217.

40-D. Zhang, Y. Tang, S. Qi, D. Dong, H. Cang, G. Lu, The inhibition performance of long-chain alkyl-substituted benzimidazole derivatives for corrosion of mild steel in $\mathrm{HCl}$, Corros Sci., 2016, $102,517-522$.

41-K. F. Khaled, Studies of iron corrosion inhibition using chemical, electrochemical and computer simulation techniques, Electrochimica Acta, 2010, 55, 6523-6532.

42-P. Muthukrishnan, P. Prakash, B. Jeyaprabha, K. Shankar, Stigmasterol extracted from Ficus hispida leaves as a green inhibitor for the mild steel corrosion in $1 \mathrm{M} \mathrm{HCl}$ solution, Arab J Chem., 2019, 12, 3345-3356.

43-M. Lebrini, M. Lagrenée, H. Vezin, M. Traisnel, F. Bentiss, Experimental and theoretical study for corrosion inhibition of mild steel in normal hydrochloric acid solution by some new macrocyclic polyether compounds, Corros. Sci., 2007, 49, 2254-2269.

44-I. B. Obot, N. O. Obi-Egbedi, N. W. Odozi, Acenaphtho [1,2-b] quinoxaline as a novel corrosion inhibitor for mild steel in $0.5 \mathrm{M} \mathrm{H}_{2} \mathrm{SO}_{4}$, Corros. Sci., 2010, 52, 923-926.

45-N. Guan, M. L. Xueming, L. Fei, Synergistic inhibition between o-phenanthroline and chloride ion on cold-rolled steel corrosion in phosphoric acid, Chem. Phys., 2004, 86, 59-68.

46-F. Bentiss, M. Lebrini, M. Lagrenée, Thermodynamic characterization of metal dissolution and inhibitor adsorption processes in mild steel/ 2,5-bis(n-thienyl)-1,3,4-thiadiazoles/ hydrochloric acid system, Corros. Sci., 2005, 47, 2915-2931.

47-X. Li, S. Deng, H. Fu, Triazolyl blue tetrazolium bromide as a novel corrosion inhibitor for steel in $\mathrm{HCl}$ and $\mathrm{H}_{2} \mathrm{SO}_{4}$ solutions, Corros. Sci., 2011, 53, 302-309.

48-F. Mansfeld, M. W. Kending, S. Tsai, Recording and Analysis of AC Impedance Data for Corrosion Studies, Corros., 1981, 37, 301-307.

49-F. Beck, U. A. Kruger, EIS of cathodically deposited wet paint films prior to the stoving process, Electrochim. Acta, 1996, 41, 1083-1092.

50-Z. El Adnani, M. Mcharfi, M. Sfaira, A. T. Benjelloun, M. Benzakour, M. EbnTouhami, B. Hammouti, M. Taleb, Investigation of Newly Pyridazine Derivatives as Corrosion Inhibitors in Molar Hydrochloric Acid. Part III: Computational Calculations, Int. J. Electrochem. Sci., 2012, 7, 3982-3996.

51-R. G. Pearson, Hard and soft acids and bases-the evolution of a chemical concept, Coordination Chemistry Reviews, 1990, 100, 403-425.

52-A. Kokalj, N. Kovačević, On the consistent use of electrophilicity index and HSAB-based electron transfer and its associated change of energy parameters, Chemical Physics Letters, 2011, 507, 181-184.

53-S. Kharacha, I. Bazzi, M. Belkhaouda, L. Bammou, A. Batah, L. Bazzi, R. Salghi, M. Hilali, Effect of L-methionine on the passivation, corrosion and inhibition behavior of tin in alkaline medium, Appl. J. Envir. Eng. Sci., 2018, 4, 339-413. 